\title{
Applying Entrepreneurship to Health Care Organizations
}

\author{
Kristina L. Guo
}

This study examines entrepreneurship and assesses its relevance to health care organizations through a detailed description of the optimal environment, organizational factors, and managerial roles in the entrepreneurship process. The article finds entrepreneurship processes to be especially useful to health care organizations as they struggle to survive in the competitive managed care environment.

$\mathrm{T}$ The U.S. health care environment is extremely turbulent, competitive, and complex. With managed care rapidly dominating the health care delivery, strategies to cut costs and improve quality and access are imperative to organizational survival. Faced with financial pressures, health care organizations are emulating market strategies and behaving more like for-profit businesses. For instance, hospitals, health maintenance organizations, and physician groups are undergoing organizational restructuring through various negotiations of contractual agreements and formation of integrated delivery systems to result in even more complex relationships. Operating under these circumstances, organizational viability has been haphazard with success harder to predict and demise a common occurrence. Strategies that rely on privatization and integration are only the beginning. Additional multidimensional strategies that analyze the environment, examine internal organizational processes, and investigate managerial traits, roles, and responsibilities are needed for long-term survival of health care organizations.

This article examines the health care industry using the concept of entrepreneurship as an appropriate approach for bettering the outlook of health care organizations. While numerous studies have been conducted on entrepreneurship in the hopes of increasing knowledge in this developing and dynamic area, most of these studies have been found in economics, business, psychology, marketing, or industrial management. That is, little research has been demonstrated on entrepreneurship in health services. Health care topics elude the use of entrepreneurship. Health care management textbooks skirt around the issue and focus only on roles and strategies of managers and their relationship to innovation and leadership. Other general health care textbooks emphasize the health care delivery system and describe the environment as turbulent. Additional research on health policy seeks to make changes in response to rising health care costs, decreased quality, and access. Unfortunately, all topics within health care research manage to evade entrepreneurship while only developing fiscal options for health care organizational survival. Delving further into the literature leads to a few articles that describe continuous technological innovations in the pharmaceutical industry (Burgelman, Maidique, and Wheelwright 2001) and entrepreneurial characteristics of senior nursing executives as "having personal integrity," "possessing a vision," and "being a strategic thinker" (Ballein 1998; Parker 1998; White and Begun 1998). There is a lack of research on the use of entrepreneurship as an important and creative technique for dealing with the complexities in the health care environment.

Due to this deficiency, this article investigates and expands upon the multidimensional use of entrepreneurship as applicable to health care organizations. The intent is to show that the need for more innovative leadership in today's health care environment can be accomplished through entrepreneurship. Entrepreneurship has been thriving in other industries and should also be used in health care to bring about growth. This research is divided into four parts. The first section defines entrepreneurship in several disciplines. The second part focuses on the U.S. health care system, particularly the external environment which has served as the subject of widespread research and policy interest. The transplantation of business entrepreneurship into health care is described in this section. As the linkage is made, it will become more apparent that entrepreneurship can and should occur in health care organizations, especially since all health care organizations face similar resource scarcity and financial complexities. Thus, the third part delves into organizational issues, including determining organizational culture that supports entrepreneurship. The final part investigates the roles of managers in the entrepreneurship process for health care organizations, particularly, traits and characteristics of managers. The article concludes by explaining the use of entrepreneurship as practical and applicable to the health care sector.

\section{Research on Entrepreneurship}

While the term entrepreneurship has been used for 
centuries, there is no single definition. Instead, researchers are continuing to expand, redefine, and innovate entrepreneurship in many different fields. For instance, entrepreneurship dates back to the 1700s by French economists and was associated with risk-bearing activities in the economy. Additional definitions of entrepreneurship refer to "an act of innovation that involves endowing existing resources with new wealth-producing capacity" (Drucker 1985). Still others define entrepreneurship as the examination of how, by whom, and with what effects to create, evaluate, and exploit opportunities and future goods and services (Shane and Venkataraman 2000). Furthermore, entrepreneurship can be related to productivity, where the entrepreneur is responsible for determining optimal production, investment, and financing decisions (Williams and Thompson 1998).

Although there is no consensus on a precise definition of entrepreneurship, one of the most commonly cited definitions is that of economist Schumpeter who used an economic model to explain the entrepreneurial process. He argued for five scenarios in which entrepreneurial innovation could occur: (1) the introduction of a new good, or of a new quality of good, (2) the introduction of a new method of production, (3) the opening of a new market (4) the conquest of a new source of supply of raw materials and (5) the carrying about of new organization in any industry (1936).

Since then, a more comprehensive approach was developed by Timmons, who defines entrepreneurship as the

....ability to create and build something from practical-

ly nothing. It is initiating, doing, achieving, and build-

ing an enterprise or organization, rather than just

watching, analyzing or describing one. It is the knack

for sensing an opportunity where others see chaos, contradiction and confusion. ... [I\}t is the willingness to take calculated risks, both personal and financial and then do everything possible to get the odds in your favour (1989).

Timmons' work suggests that external factors influence and shape the success of entrepreneurship. He also claims that the key to successful entrepreneurship is understanding opportunity, being able to match the organization and situation to the key players (1989). Furthermore, Kuratko and Hodgetts assert that entrepreneurship is made up of multidimensional processes involving the environment, organizations, and individuals (1998).

\section{The External Environment}

The environment plays a crucial role in the creation of entrepreneurship. The external environment is made up of two parts: the societal environment and task environment (Kuratko and Hodgetts 1998). The societal environment encompasses economic, political, legal, and technological forces that influence long-term decisions of organizations. The task environment is made up of elements that are directly affected by an organization's operations.

\section{Societal Environment}

The societal environment can be illustrated by the current state of the U.S. economy which is experiencing sharp decline, as more businesses are forced to lay off employees or even worse file for bankruptcy. In the midst of this turmoil, policies are aimed at improving the economy by dropping interest rates, which makes it easier to acquire loans. On the technology side, dotcom companies are struggling to survive. Under these circumstances, the environment can be described as lean, lacking access to resources, and tending to promote more competitive practices. These factors challenge organizations' quest for growth and profitability and has led to the demise of many organizations (Zahra and Neubaum 1998). On the other hand, many organizations can survive, succeed, and thrive under these harsh environment conditions. In fact, adverse environments force organizations to innovate, take risks, and become entrepreneurial (Zahra and Covin 1995). Entrepreneurial strategies can help an organization move to richer environments by improving its operating practices, innovating its strategies, and enabling it to merge with other organizations. In other words, when societal environment forecasts a gloomy picture, entrepreneurial activities can be promoted to enhance organizational growth.

For example, in the battles for control of the automobile industry, Henry Ford's innovative strategy for Ford Motor Company was based on improving its operating practices through "vertical integration, carefully engineered production, and product simplicity" (Burgelman, Maidique, and Wheelwright 2001). Thus, Ford introduced mass-production and mass-market techniques. However, William Durant, owner of Buick Motors, sought a different strategy in which he proposed mergers with other companies. He found the automobile industry to be swamped by hundreds of carmakers each only producing a few models. Operating in such a competitive environment, Durant believed that manufacturers would benefit by banding together. His strategy, "based on acquisitions of smaller companies, marketing power, sales coverage, and product variety" (Burgelman, Maidique, and Wheelwright 2001), led to the creation of General Motors (GM). Although GM was created in 1908, today, it continues to steer around competitors and maintain its status as the world's number one maker of cars and trucks.

Wal-Mart Stores, the world's leading retailer, has successfully crushed its competitors using its basic strategy of supplying well-known brands in sparsely populated areas and offering products 15 percent lower than other stores in the same location. It began in 1962 as a discount store in 
Arkansas. Wal-Mart maintains its small-town flavor, and is famous for low prices, friendly workers, patriotic products, and a wide selection of merchandise, including food, clothing, electronics, and prescription drugs. In fact, its prescription drug sales make it North America's third largest pharmacy. With the opening of its Supercenters that focus on groceries, Wal-Mart is now the nation's largest seller of groceries.

The 2001-2002 U.S. economic recession poses a different yet equally daunting challenge for large corporations. In the case of General Electric Company (GE), to recover from economic slowdown, it has "adopted a strategy of pursuing only high-achieving ventures and dumping those that didn't perform" (Hoover's Company Profile Database 2003). New CEO Jeff Immelt understands that the current lean economic environment affects not only GE, but also businesses that depend on GE services. His innovative efforts to maneuver in this environment include expansion of services outside of the United States and conducting more business on the web.

The four cases above describe the ability by large corporations to develop and sustain entrepreneurial activities in spite of the competition. In-depth scrutinizing and understanding of forces in the external environment led to the exploitation of multidimensional strategies to produce successful outcomes.

\section{Task Environment}

The task environment refers to the specific industry environment. Examples of entrepreneurial activities in other industries, such as the automobile, telecommunications, and computers can provide advice and warnings to the health care industry. The above descriptions of Ford's and GM's strategies only skimmed the surface; further illustration of these two companies lead to a greater understanding of the need for entrepreneurial strategies in response to industry challenges. Two notable struggles occurred in the automobile industry. The first was the 1930s' battle between automakers and workers. Working conditions were dangerous and laborers protested. As a result, the United Auto Workers Union was formed. It brought workers bargaining power and protection at a high cost of "work-rule rigidity and the polarization of workers and management" (Burgelman, Maidique, and Wheelwright 2001). Labor-management struggles continued into the 1970s, until the second significant industry challenge took on precedence. The U.S. auto industry nearly collapsed with the emergence of the Japanese automobile. Toyota combined "product variety, quality and efficiency.... with customer-focused design, concurrent engineering, flexible manufacturing, dedicated workers and networks of suppliers" (Burgelman, Maidique, and Wheelwright 2001). To defend against this new wave of business rivals, major U.S. automakers engaged in innovative entrepreneurial practices that led to the total transformation of the auto industry. It resulted in competitive collaboration. Toyota's joint venture with GM and Mazda's with Ford allow these automakers the opportunity to assess the progress of their rivals and learn from them.

Similarly, the telecommunications industry also experienced enormous changes. The American Telephone and Telegraph (AT\&T) Company monopolized the telecommunications industry from 1877 to 1970s. To accomplish this feat, CEO Theodore Vail's first strategy was to buy out its competitors. In danger of an antitrust lawsuit, Vail launched a major lobbying campaign to convince government that having a single telephone company was in the best interest of the nation. Having been recognized as a monopoly, Vail promised universal services and its profits would fund local services and research. However, in 1968, a breach of AT\&T's monopoly occurred when the Federal Communications Commission allowed equipment suppliers to compete with AT\&T. In 1974, AT\&T lost its monopoly status when $\mathrm{MCl}$ filed an antitrust suit and won. Since then, the telecommunications industry has evolved into hypercompetition with its four markets: wireline, wireless, cable, and internet. AT\&T must now coexist and struggle for market share with competitors. Realizing that AT\&T has lost the majority of its long-distance business, CEO C. Michael Armstrong pursued aggressive multidimensional strategies to acquire the broadband, cable, and internet sectors which allow AT\&T to penetrate all four segments of the market, thereby offering customers a "one-stop shopping" convenience (Burgelman, Maidique, and Wheelwright 2001).

Likewise, Tandy Corporation and Apple Computers introduced the personal computer (PC) industry in the late 1970s through their revolutionary packaging of hardware, software, and services. Apple's strategy relied on cooperation with independent software developers, while Tandy took on a vertically integrated approach. Tandy's tight control over its organization resulted in slower growth, while Apple's reliance on participation with other companies led to its larger market domination. International Business Machines (IBM) entered the PC industry in 1981. It also took on Apple's strategy of building on a community of partners. IBM generated more demand than it could meet. As a result, it developed nonexclusive relationships with suppliers, such as Microsoft, Intel, and Lotus, to help meet demand. Unfortunately, IBM did not take precautions to enforce its patents against clone makers. Thus, other suppliers were able to put together common standards for hardware and software without IBM's involvement. This ultimately led to the decline of IBM products as Intel and Microsoft now dominate the new computer market. IBM's failings occurred in its expansion stages when it could not keep up with innovations, while Intel surpassed with the innovative microchip and Microsoft with its software packages (Burgelman, Maidique, and Wheelwright 2001). 
Successes and failures in entrepreneurial activities of other industries serve as guidance for the health care industry. In the health care industry, the task environment is made up of providers (i.e., hospitals, physicians), suppliers (i.e., pharmaceutical companies), competitors, patients, special interest groups (i.e., American Association of Retired Persons, Health Insurance Association of America), and governments (federal, state, and local). The health care industry has been depicted as turbulent (Shortell and Kaluzny 2000), which is characterized by highly complex and fast-paced changes, particularly due to the rapid growth of managed care as a strategy for lowering costs, improving access and quality. Furthermore, it is also made complex by the multitude of interests directly and indirectly involved in the delivery of health care. That is, private sector businesses are largely responsible for the development and delivery of drugs and medical supplies while government agencies regulate its actual delivery (Ginter, Swayne, and Duncan 2002). Thus, in times of turbulence, the ability to anticipate changes, recognize external forces, and meet the needs of the market greatly enhances the chances of success.

Forces that affect the health care industry include aging of the population, increasing ethnic and cultural diversity, growth of new technology, especially medical advancements, changes in supply and education of health professionals, social morbidity that changes from acute to chronic care, and globalization of the world economy (Shortell and Kaluzny 2000). For example, 13.2 percent of the gross national product was spent on medical care in the United States in 2000 (Levit, et al. 2002). The federal government estimates that national health expenditures will rise at a higher rate as baby boomers become eligible for Medicare and as new technology becomes available to improve quality of life. Those over 65 years old, who currently represent 12.3 percent of the population, fill 40 percent of hospital beds (Reinhardt, Hussey, and Anderson 2002). At the same time, government continues to subsidize the health care demands of the aged and poor, which means a heavier burden for the working population. At the societal level, choices are considered and must be made to decide upon the amount of resources to be spent on providing health services. Those decisions, not easily made by governmental policies, influence individual health care organizational priorities.

Health care organizations are affected by societal environment changes and their own industry changes, even though organizations may vary by complexity, susceptibility to change, and competitiveness. For example, hospitals exist in highly competitive, complex, and rapidly changing environments. Government policies that emphasize cost containment have pressured hospitals to perform more efficiently and cost effectively. To do so, hospitals must innovate by restructuring to form horizontal and vertical integrated delivery systems. As a result, two major cate- gories of healthcare systems have emerged: (1) geographically scattered systems have a small market share in each of many different health care regions and (2) geographically focused systems attempt to capture substantial market share in one or a small number of geographic areas. Many church-related health care systems and forprofit organizations follow the former model, while larger health care systems resemble the latter (Griffith 1999).

Kaiser Permanente (KP), the nation's largest health care system, has been able to replicate its geographically focused model in many different sites. It is the nation's oldest independent, prepaid group practice, serving the health care needs of more than 6.5 million members in 16 states and the District of Columbia. In 1990, KP's revenue totaled $\$ 8.4$ billion. KP, a not-for-profit practice, represents a prototype health care organization in the changing health care environment. It combines the insurance function with the delivery function while providing a continuum of care to its defined populations. KP encompasses three organizations, Kaiser Foundation Health Plan, Kaiser Foundation Hospitals, and the Permanente Medical Groups. The Health Plan contracts with individuals and groups to provide health care benefits through its Hospitals and Medical Groups. The Hospital Groups own and operate community hospitals and outpatient facilities. The Medical Groups form partnerships with physicians (Shortell and Kaluzny 1997). KP is a leading health care organization and many of its strategies exemplify the concept of entrepreneurship. Specifically, the KP strategic model of integrating all components of service delivery is emulated by other health care organizations, particularly managed care organizations. KP's ability to establish effective physician relationships through its Medical Groups serves as a model for other health care systems that seek to combine physicians with hospitals. KP is a leader in the development of information systems that tie together patients and providers across the continuum of care to produce high organizational performance. In fact, KP's entrepreneurial activities have long established its status as a benchmark organization, thereby setting best industry practices for other organizations to follow.

Other examples of large health care systems include Intermountain, serving most of Utah and parts of adjacent states; Mayo, operating in Minnesota, Arizona, and Florida; Uni-Health in southern California; Henry Ford Health System in southeast Michigan; and Geisinger in Pennsylvania. The entrepreneurial activities of these health care systems are exemplified by their multifacet approaches to exchange with the open environment, align partners, improve their processes, and empower workers (Griffith 1999).

Another innovative way for health care systems to expand their market share has been the conversion from not-for-profit status to for-profit status. This change signifies the industry's movement toward more business-like 
practices. For example, the Health Maintenance Organization (HMO) of Pennsylvania converted to a forprofit status in 1981 to become U.S. Health Care Systems, Inc. In this way, it was able to obtain venture capital investments.

A prominent example of a large health care corporation undertaking entrepreneurial activities in response to demands in the environment is the case of Blue Cross (BC) and Blue Shield Association. BC was established in 1929 as the precursor to managed care when Baylor University offered schoolteachers prepaid hospital care for $\$ 6$ a year. By 1935, 11 states operated BC plans. In 1946, as states began sponsoring prepaid plans to cover physician fees, Blue Shield was created. By 1960, BC insured about one third of the U.S. population. In the next decade, BC administered Medicare and other government health plans. By 1970, half of BC's premiums came from government entities. In response to consumer demands for preventive care, BC and Blue Shield shifted their focus to prevention. Furthermore, they adopted hospital control measures. As the two organizations lost market share to other competitors, their major strategy led to the merge of the two organizations in 1982. To remain viable in the highly competitive environment, Blue Cross and Blue Shield (BCBS) engaged in several entrepreneurial activities, including converting to a for-profit status, merging and forming alliances with other health care organizations, and expanding globally. The BC of California became the first chapter to give up its tax-free not-for-profit status when it was bought by WellPoint Health Networks, a managed care subsidiary. Other BCBS soon followed in the switch to for-profit status. BC of Connecticut merged with insurance provider Anthem in 1997. Anthem later acquired and formed affiliates with BCBS in Colorado, Maine, and New Hampshire. Empire BCBS of New York converted to a for-profit practice in 2000. Half of the nation's BCBS operators formed an alliance called BluesCONNECT as a strategy to compete with national health plans by offering employers one nationwide benefits organization. In an unprecedented lawsuit of BCBS in 35 states against the tobacco industry, BCBS gained large settlements to treat patients with smoking-related illnesses. A final innovative strategy is BCBS's move to assemble a network of caregivers in Europe, South America, and Asia in its efforts to aim at worldwide health care coverage (Hoover's Company Profile Database 2003).

The health care industry, similar to the automobile, telecommunications, and computer industries, is becoming increasingly complex and competitive and has resulted in interorganizational networks (Shortell and Kaluzny 2000). Under these harsh environmental conditions, entrepreneurship activities that have succeeded in other industries are transplanted to the health care industry to promote success.

\section{Internal Environment: The Organization}

The external environment heavily influences the functions of the internal environment, which consists of the organization itself, its structure, culture, and resources. Organization structure describes its authority, communication, and work flow. Culture is the pattern of beliefs, value, and behaviors shared by the organization's members. Resources are the assets used to form the organization's products and services. As the external environment becomes more turbulent, the internal organization must take measures to reduce uncertainty.

According to a study conducted by Moon (1999), structural factors in the organization that affect entrepreneurship include hierarchy, formalization, and centralization. More levels of hierarchy lead to extra layers of communication and more managerial burdens in decision-making processes and tasks. In this way, managers are less likely to engage in risk-taking behaviors since they require added time and effort to gain communication approvals. Similarly, a formalized structure with required paperwork and written rules tends to cause administrative delay and poor communications and results in reductions in managerial risk-taking and entrepreneurial activities. Centralization affects entrepreneurship in two ways. In a centralized organization, senior-level managers have more authority over their subordinates. On the other hand, middle- and lower-level managers have less decisionmaking authority. Thus, a centralized structure offers more risk-taking opportunities for top managers, yet it restricts entrepreneurship activities for middle- and lower-level managers.

In the automobile industry, both Ford and GM were able to innovatively manage their mega bureaucratic operations through decentralized management. Sloan, president of GM from 1923 to 1937 created the multiproduct lines for its diverse company, so that GM became the prototype of the modern multidivisional company. In health care, multidivisional designs are found in most academic health centers that operate in highly uncertain environments combined with complex organizational relationships formed between medical schools and hospitals. For instance, the University of Miami/Jackson Memorial Medical Center is an example of a multidivisional design.

Maintaining and/or altering structure is initiated by senior-level management. Thus, senior-level managers are responsible for entrepreneurial activities such as risktaking decisions. Entrepreneurial changes and innovations include fundamental design and structure of reporting relationships and authority, clinical and managerial information systems, management control systems and goals, policies, and directions of the organization. In some cases, organizations are innovating to gain greater operational flexibility and control, more rapid decision making and sharing resources. 
For instance, going back to the case of Wal-Mart, the retailer has capitalized on three organizational capabilities: (1) building incentives to ensure employee commitment, (2) communicating with remote located stores, and (3) setting up an efficient distribution system that allows for joint purchasing, shared facilities, and systematic ordering. The latter strategy is Wal-Mart's trademark whereby warehouses serve a group of stores no more than a day's drive from the distribution center (Burgelman, Maidique, and Wheelwright 2001). Thus, Wal-Mart has been able to share resources while gaining operational flexibility.

A health care example of operational flexibility and sharing of resources is shown by the partnership between the Somerville Hospital and Cambridge Hospital in Massachusetts to form the Community Care Network program. Community needs assessments were conducted in both cities and identified similar top priorities. As a result, they collaborated to create the Somerbridge Community Health Partnership to coordinate health care needs for both communities. Their collaborative efforts resulted in the sharing of resources and greater opportunities for residents to gain access to health care (Shortell and Kaluzny 2000).

Organizational culture is considered a key element that promotes entrepreneurship in organizations; hence, it is a critical factor that determines success or failure of organizational entrepreneurial activities (Moon 1999). Changes in culture must be incorporated into organizational reform strategies to enhance entrepreneurship. These changes include emphasizing higher levels of trust and mission clarity and valuing employees' commitment and contributions to the organization. For example, Baptist Medical Center in Birmingham believes its Christian values and missions are essential to the organization's success. Thus, it redeveloped its mission statement to outline four core values: quality care, individual dignity, cost efficiency, and community support. This strategic maneuver helped to strengthen the organization's culture and values and enabled employees to gain a sense of stability in the complex and uncertain environment (Hernandez, Kaluzny, and Haddock 2000).

Entrepreneurship activities enhance organizational positions, and involve a company's innovation, venture activities, risk taking, proactiveness, and radical product innovation (Zahra, Nielson, and Bogner 1999). In the case of Sunnybrook Health Sciences Center, an academic health science center affiliated with the University of Toronto, the challenges were enormous as it operated in an environment of high costs, lowered revenue, limited funding sources, and high patient expectations of quality and outcomes. CEO Tom Closson took on a radical restructuring and risk-taking strategy to create a patientfocused care center. The five-pronged approach emphasized decentralizing various clinical units, bringing services to patients, promoting shared decision making, consolidating roles and scopes of practice of support and clinical staff, and continuous monitoring to maintain the patient-focused center (Leatt, Shortell, and Kimberly 2000).

Entrepreneurship activities should be used by health care organizations to improve organizational growth and profitability and promoted as a means of achieving more efficient, flexible, and adaptable management in turbulent and competitive environments.

\section{Managerial Traits, Behaviors, and Roles that Foster Entrepreneurship}

Entrepreneurship can be characterized by the individuals who are responsible for new ideas, fundamental change, and risk taking to bring about organizational success (Bull and Willard 1995; Kuratko and Hodgetts 1998). Entrepreneurship activities originate from individuals whose traits, skills, behaviors, and background are crucial for entrepreneurial activity development.

Entrepreneurs are persons who perceive opportunities and assume the risks of planning and creating various means to pursue them. Common characteristics of successful entrepreneurs were identified by McGrath and MacMillan (2000) as (1) passionately seeking new opportunities, (2) pursuing opportunities with enormous discipline, (3) pursuing only the best opportunities by linking choice of options with strategy, (4) focusing on adaptive executive, and (5) engaging the energies of everyone in their domain. Chell, Haworth, and Brearley (1991) describe traits of entrepreneurs as self-confidence, risk taking, flexibility, strong desire to achieve, and independence. They point out that behaviors include total commitment, determination and perseverance, drive to achieve and grow, and orientation to goals and opportunities.

Miner created a four-way psychological typologies of successful entrepreneurs as:

...(1) the personal achiever type, who is prone to motivated for self achievement, (2) the real manager type who demonstrates high supervisory ability and strong need for occupational advancement, (3) the expert idea generator who enjoys coming up with original or innovative ideas and (4) the empathic supersalesperson type who is sociable, friendly and supportive and encourage participation and is action oriented (1997).

Certainly, Henry Ford, Alfred Sloan of GM, and Sam Walton of Wal-Mart are just a few examples of successful entrepreneurs. In health care, the specific role of a manager responsible for making significant changes has most commonly been identified as that of leader. As a leader, one must articulate and internalize the values of the organization, according to Edward J. Connors, past president of Mercy Health Systems and former chair of the American Hospital Association's Board of Trustees (Zuckerman and Dowling 1997). Managers can also be characterized as strategists and designers (Zuckerman, Dowling, and Richardson 2000). As strategists, managers must monitor and analyze the environment prior to employing a variety 
of strategies to meet those changing needs. As designers, managers are responsible for managing organizational structure, innovation, and change. Another role of the manager is that of the entrepreneur, responsible for initiating and designing change in an organization (Mintzberg 1973). Rakich, Longest, Jr., and Darr describe Mintzberg's entrepreneur role as that of "change agent." That is, health services organizations "are internally dynamic and continuously affected by their environment. Managers must seek to improve, modify, and rearrange work through planned, conscious, and controlled change" (1992).

A health care manager's role involves various types of changes and innovations. These could range from introduction of new products and services or redefining an organization's goals. In the previous discussion of Sunnybrook, CEO Closson drastically restructured his organization to meet the needs of patients. In the case of Lutheran Health Systems, CEO Michael Bice overhauled the entire organization to create a new proactive culture where continuous, personal, and hands-on commitment is a priority (Zuckerman and Dowling 1997). Another example is that of CEO Joseph A. Zaccagnino of Yale New Haven Health System. He believes success depends on aligning strong health care organizations (i.e., three major hospitals) to a shared vision to create a leading integrated delivery system. Furthermore, he recommends managers to have broad skills, enabling them to evolve in complex enterprises (Grazier 2003). As health care managers continue to expand their roles to develop innovations, they rely more on entrepreneurial traits, behaviors, and skills to result in their organizational growth.

\section{Entrepreneurship: Applicability to Health Care Organizations}

The health care industry is similar to other industries in environment conditions, structure, and strategies. Industries such as automobile and telecommunications have undergone massive transformations in their environment and organizational structure and strategies. Commonalities in their environment include turbulence, inflexibility, and competitiveness. Structural similarities include new entrants, mergers, and consolidation. Strategies have shifted to cost accounting and management and strategic alliances. These scenarios are very similar to the health care industry, since it is also characterized by turbulent and harsh environment conditions. In light of these environment variables, health care has undergone structural and strategic changes and innovations to achieve organizational economies of scale, improve utilization of resources, enhance access to capital, increase political power, and extend the scope of the market (Zuckerman, Dowling, and Richardson 2000). Samaritan Health System in Arizona, Sutter Health in California, Intermountain Health Care in Utah, and Kaiser Permanente are examples of health care systems that have undergone strategic and structural changes to improve patient care and establish competitive distinction in their regions. Hospitals in the Rochester, New York, area have formed a voluntary alliance to contain duplication of services which resulted in impressive cost reductions (Zajac and D'Aunno 1997). Similarly, hospitals in the New England area formed the Yankee Alliance. Although challenges included reductions in membership, the benefits of shared resource and market power have been rewarding (Zajac, D'Aunno, and Burns 2000). Among the various industries, similarities exist in the environment, organizational structures and managerial behaviors; thus, multidimensional strategies emphasizing entrepreneurship practices can take place and become effective in health care industry.

Moreover, Chicken (2000) explains that industries conduct entrepreneurial activities for the exploitation of profits or benefits. In private businesses, entrepreneurial activities result in profit measured by monetary terms. As more health care organizations convert to for-profit status, entrepreneurial activities would occur when they vie for market share and profits. In other cases, profit or benefits cannot be measured by money. In not-for-profit health care organizations, the benefit of medical treatment can be assessed by organizational survival, reputation, growth and opportunities. Thus, these scenarios also require multidimensional strategies and necessitate the use of entrepreneurship in health care organizations. In fact, the complex health care environment demands more innovative solutions. Consequently, health care organizations are beginning to utilize entrepreneurship in their management techniques.

Another example of the applicability of entrepreneurship to the health care industry is described by Chicken (2000). $\mathrm{He}$ offers a number of entrepreneurial activities for a range of industries. For instance, he finds these activities in financial services (banking and insurance industries), manufacturing, agriculture, transportation, mining, fishing, hotels, media, civil services and government. He further summarizes that entrepreneurial activities occur under three circumstances. First, operations must be carried out in the open market. Second, some operations must be funded or subsidized by government. Third, operations could be completely funded by government. Using this formula, it is clear that entrepreneurial activities can occur in the health care industry, since health care organizational activities satisfy the first two criteria.

Moreover, Chicken suggests that there are many levels of entrepreneurial activities and they depend on the level of management responsibility (2000). For example, managers who are the decision-makers in the organizations must be prepared to react to changes in a flexible and positive manner. Thus, in current times of uncertainty, complexity, and resource scarcity, health care organizations rely on their managers to redefine their roles to enable their organizations to gain the competitive edge. The use of process-based managerial entrepreneurship (Moon 1999) refers to the improvements in administrative procedures, intraorganizational communications, and introrganizational interactions. In other words, flexible 
decision-making processes, open channels of communication and simplification of work processes in organizational innovations are more readily used and have become more important to health care organizations. These processes are, in fact, entrepreneurship processes, as managers increase their entrepreneurial role to become involved in risk-taking strategies and serve as agents of change. Multidimensional steps are necessary to assess the environment and organization prior to making changes using innovative strategies. Indeed, entrepreneurship is applicable to the health care industry as it has been successfully utilized in other industries.

\section{Conclusions}

This study has made the linkage between entrepreneurship and health care so that entrepreneurship should be promoted by health care organizations to better their chances of survival. The environment, organizational structure, and strategies of health care organizations have necessitated the use of entrepreneurship. Specifically, reliance on the entrepreneurial manager is the key to surviving difficult times and achieving success. While this study only takes the first step in establishing the relevance of entrepreneurship to health care, it serves as a bridge for furthering that knowledge into health care.

\section{References}

Ballein, K. M. 1998. Entrepreneurial leadership characteristics of SNEs emerge as their role develops. Nursing Administration Quarterly 22, 2: 60-69.

Bull, I., and G. Willard. 1995. "Towards a theory of entrepreneurship," in I. Bull, H. Thomas, and G. Willard, eds., Entrepreneurship: Perspectives on theory building. Oxford: Elsevier Science Ltd, pp.1-6.

Burgelman, R. A., M. A. Maidique, and S. C. Wheelwright. 2001. Strategic management of technology and innovation, 3rd ed. Boston, MA: McGraw-Hill.

Chell, E., J. Haworth, and S. Brearley. 1991. The entrepreneurial personality: Concepts, cases and categories. London: Routledge.

Chicken, J. C. 2000. Management and entrepreneurism. London: Thomson Learning.

Drucker, P. F. 1985. Innovation and entrepreneurship. New York: Harper and Row.

Ginter, P. M., L. E. Swayne, and W. J. Duncan. 2002. Strategic management of health care organizations, $4^{\text {th }}$ ed. Oxford: Blackwell Publishers.

Grazier, K. L. 2003. Interview with Joseph A. Zaccagnino, president and CEO of Yale New Haven Health System. Journal of Health Care Management 47, 5: 283-286.

Griffith, J. R. 1999. The well-managed healthcare organization, 4th ed. Chicago: Health Administration Press.

Hernandez, S. R., A. D. Kaluzny, and C. C. Haddock. 2000. "Organizational change and innovation," in S. M. Shortell and A. D. Kaluzny, eds., Health care management: Organization design and behavior, 4th ed. Albany: Delmar Publishers, pp. 330-355.

Hoover's Company Profile Databases_American Public Companies. 2003. Austin, TX: Hoover's Inc.

Kuratko, D. F., and R. M. Hodgetts. 1998. Entrepreneurship: A contemporary approach, 4th ed. Forth Worth, TX: Dryden Press.

Leatt, P., S. M. Shortell, and J. R. Kimberly. 2000. "Organization design," in S. M. Shortell, and A. D. Kaluzny, eds., Health care management: Organization design and behavior, 4th ed. Albany: Delmar Publishers, pp. 274-306.

Levit, K., C. Smith, C. Cowan, H. Lazenby, and A. Martin. 2002. Inflation spurs health spending in 2000. Health Affair 21, 1: $172-181$.

McGrath, R. G., and I. MacMillan. 2000. The entrepreneurial mindset: Strategies for continuously creating opportunity in an age of uncertainty. Boston: Harvard Business School Press.

Miner, J. B. 1997. A psychological typology of successful entrepreneurs. Connecticut: Quorum Books.

Mintzberg, H. 1973. The nature of managerial work. New York: Harper-Row.

Moon, M. J. 1999. The pursuit of managerial entrepreneurship: Does organization matter? Public Administration Review $59,1: 31-46$.

Parker, M. 1998. The new entrepreneurial foundation for the nurse executive. Nursing Administration Quarterly 22, 2: 13-21.

Peterson, R., and D. Berger. 1971. Entrepreneurship in organizations. Administrative Science Quarterly 16: 97-106. 
Rakich, J. S., B. B. Longest, Jr., and K. Darr. 1992. Managing health services organizations, 3rd ed. Baltimore: Health Professions Press.

Reinhardt, U. E., P. S. Hussey, and G. F. Anderson. 1999. Cross-national comparisons of health systems using OECD data. Health Affairs 21, 3: 169-181.

Schneider, M., and P. Teske, with M. Mintrom. 1995. Public entrepreneurs: Agents for change in American government. New Jersey: Princeton University Press.

Schumpeter, J. A. 1936. The theory of economic development, 2nd ed. Cambridge, MA: Harvard University Press.

Shane, S., and S. Venkataraman. 2000. The promise of entrepreneurship as a field of research. Academy of Management Review 25, 1: 217-227.

Shortell, S. M., and A. D. Kaluzny. 1997. "Organization theory and health services management," in S, M. Shortell and A. D. Kaluzny, eds., Essentials of health care management. Albany, Delmar Publishers, pp. 3-3.

Shortell, S. M., and A. D. Kaluzny. 2000. "Organization theory and health services management," in S. M. Shortell and A. D. Kaluzny, eds., Health care management: Organization design and behavior, 4th ed. Albany: Delmar Publishers, pp. 4-3.

Timmons, J. A. 1989. The entrepreneurial mind. MA: Brick House Publishing.

White, K. R., and J. W. Begun. 1998. Nursing entrepreneurship in an era of chaos and complexity. Nursing Administration Quarterly 22, 2: 40-47.

Williams, E. E., and J. R. Thompson. 1998. Entrepreneurship and productivity. New York: University Press of America.

Young, R.C., J. D. Francis, and C. H. Young. 1999. Entrepreneurship: Private and public. New York: University Press of America.

Zahra, S., and J. Covin. 1995. Contextual influences on the corporate entrepreneurship company performance relationship in established firms: A longitudinal analysis. Journal of Business Venturing 10, 1: 43-58.

Zahra, S. A., and D. O. Neubaum. 1998. Environmental adversity and the entrepreneurial activities of new ventures. Journal of Developmental Entrepreneurship 3, 2: 123-140.

Zahra, S. A., A. P. Nielsen, and W. C. Bogner. 1999. Corporate entrepreneurship, Knowledge and competence development. Entrepreneurship: Theory and Practice 23, 3: 169-185.

Zajac, E. J., and T. A. D’Aunno. 1997. "Managing strategic alliances," in S. M. Shortell and A. D, Kaluzny, eds., Essentials of health care management. Albany: Delmar Publishers, pp. 328-354.

Zajac, E.J., T. A. D’Aunno, and L. R. Burns. 2000. "Managing strategic alliances," in S. M. Shortell and A. D. Kaluzny, eds., Health care management: Organization design and behavior, 4th ed. Albany: Delmar Publishers, pp. 307-329.

Zuckerman, H. S., and W. L. Dowling. 1997. "The managerial role," in S. M. Shortell, and A. D. Kaluzny, eds., Essentials of health care management. Albany: Delmar Publishers, pp. 34-62.

Zuckerman, H. S., W. L. Dowling, and M. L. Richardson. 2000. "The managerial role," in S. M. Shortell and A. D. Kaluzny, eds., Health care management: Organization design and behavior, 4th ed. Albany: Delmar Publishers, pp. 34-60.
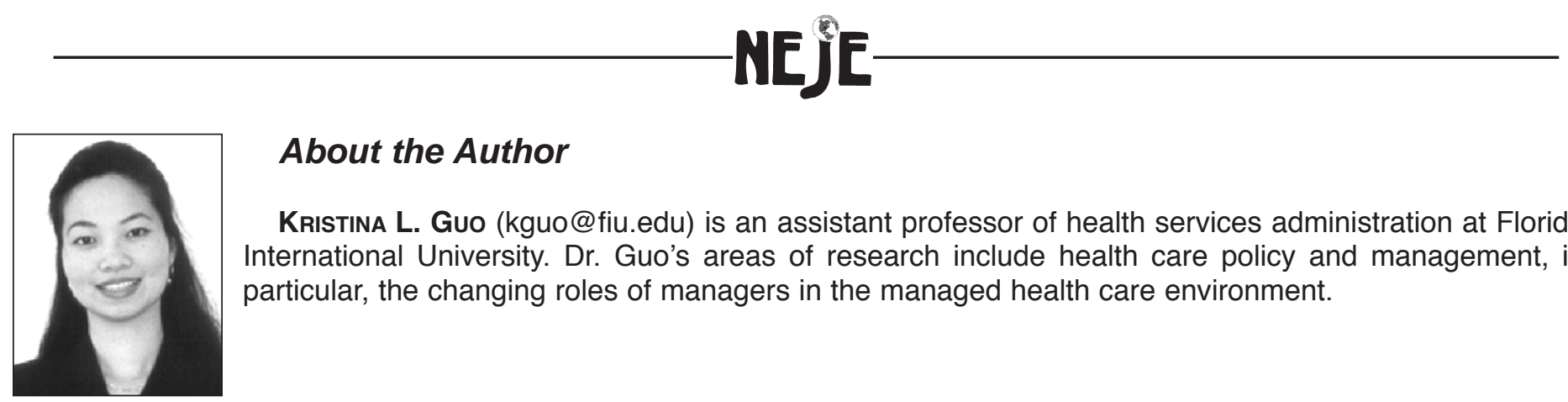

\section{About the Author}

Kristina L. Guo (kguo@fiu.edu) is an assistant professor of health services administration at Florida International University. Dr. Guo's areas of research include health care policy and management, in particular, the changing roles of managers in the managed health care environment. 